\title{
Analysis of hysteresis in convergence after global financial crisis of 2007
}

\author{
Archana Kumari $^{1 *}$, Evgeny Kuzmin ${ }^{2,3}$, and Vikas Kumar ${ }^{1}$ \\ ${ }^{1}$ University of the West of England, Bristol Business School, Bristol, BS16 1QY, UK \\ ${ }^{2}$ Institute of Economics of the Ural Branch of the Russian Academy of Sciences, Ekaterinburg, \\ 620014, Russian Federation \\ ${ }^{3}$ Ural State University of Economics, Ekaterinburg, 620144, Russian Federation
}

\begin{abstract}
Researchers of hysteresis outline the long-term change in growth paths of economies. It entails the post-crisis change in growth paths of economies through the change of macroeconomic indicators, such as employment and output. Recessionary shocks might have positive or negative impacts on economies' growth paths which in turn affects convergence and divergence in economies. In this research, hysteresis is explored in convergence across 110 countries induced by the global financial recession of 2007. Findings suggest that as a post-crisis change, hysteresis in convergence is in place. The difference arises in adaptability of economies to changes. The reason for convergence of poor and rich countries might be more intensive foreign investments in developing nations. These investments have a positive influence on economic performance in developing countries by increasing employment rates.
\end{abstract}

Key words: convergence, divergence, hysteresis, regional differences.

\section{Introduction}

Economic growth convergence is both a well-explored and highly debatable subject. Researchers went through different stages of subject development and clarified many doubts. However, the impact of the crisis of 2007/2008 on convergence still needs attention. It has been more than a decade after the crisis and many economies have been still in a struggle to get back to pre-crisis output levels. Although the reasons that are behind lagging economies not catching up with their counterparts have been explored a lot, the effect of the crisis on non-linear behaviours (hysteresis) in economies has not been discussed in full in the literature. It is known that the economic crisis causes non-linearity (hysteresis) in behaviours of economies. The question whether it reflects non-linearity in aggregate convergence processes has been still waiting for further investigations. This study will show evident nonlinear behaviours of economies induced by the global crisis of 2007 and changes in dynamics of convergence across the world. In this paper, the crisis will help to analyse behaviours of economies and their influence on convergence dynamics.

\footnotetext{
* Corresponding author: Archana.Kumari@uwe.ac.uk
} 
Convergence was originally related to the economies that approach their steady-state levels of output or growth paths. This definition was interpreted to provide a macro picture of convergence across economies: capital-poor economies catching up with capital-rich economies. According to mainstream economists, the law of diminishing marginal returns prevails on capital that makes the return on capital for capital-rich economies less attractive. Hence, investments go to capital-poor economies where the potential to earn more returns is higher. Gradually, the returns or factor prices of capital become equal in both economies. Similar mobility of labour is in pace (from capital-poor economies to capital-rich economies). Thus, mobility and price equalisation factors provide a basis for faster growth of poor economies and their convergence with richer economies at the output level in the long term [1-3]. Furthermore, mainstream economists assume the linear model across economies suggesting that every economy is at the common steady-state growth path. The linear relationship implies that explanatory variables (e.g., physical, and human capital, technology) have the same causal effects on the dependent variable (GDP) across economies.

However, growing inequality between economies does not clearly reflect occurrence of convergence. Assumed diminishing marginal returns and linear model were criticized by researchers in favour of increasing returns and non-linear model. In this regard, Quah [4-8] provides many important insights in mainstream dynamics of convergence by offering his distributional dynamics-based analysis and shows persistent inequality in economies through application of the distribution dynamics technique using global income data. Afterwards, the analysis of distribution dynamics gained attention. Since then, researchers have started to highlight importance of relative behaviours of economies in the pairwise setting. In this research, therefore, we used the pairwise technique (called X-convergence and proposed by [9-10]) in convergence evaluation.

The research aims at an analysis of the change in convergence/divergence patterns in terms of hysteresis. We refer to convergence as a one-time shock to economy with a longterm effect on economic variables that caused a drastic change in convergence (adapted from [11]). Economic hysteresis is a non-linear behaviour described with a shift from one trend to another trend of behaviour after a loop caused by the crisis. Among resilience researchers, Martin [12] theorises hysteresis. He considers hysteresis in terms of a recessionary shock disrupting economic growth and development. Empirically, Tubadji et al. [13] studied this disruption while investigating investment behaviours of entrepreneurs after the shock. In this research, we will analyse how the economic shock of 2007/2008 led to hysteresis in convergence.

The rest of the chapter is organised as follows: Section 2 provides hysteresis background. Section 3 provides information on data and choice of time periods and outlines the method. This chapter presents convergence dynamics in pre- and post-crisis periods. Section 4 includes findings of the data analysis. Section 5 presents conclusions of the chapter.

\section{Literature review}

In some economies, hysteresis is an important after-effect of the crisis. As discussed earlier, the non-linear behaviour is prominent from categorising economies with different convergence characteristics. In this context, economists often explain possibility of multiple equilibrium or domains with the help of the theory of 'hysteresis' [14-17]. The theory of hysteresis in economy has evolved over time [18-21]. Cross and Allan [22] define hysteresis as a long-lasting effect of a temporary stimulus. Similarly, Romer [11] states that hysteresis occurs when a shock disturbs a path of an economy in the long term.

Researchers shown that the regions that are frequently exposed to economic downturn trends show a decline in long-term growth rates. They disrupt networks and linkages that influence growth paths and trajectories of regions in the future [23-24]. As a result, a 
depressed economy needs to channel its resources and restructure its agents to provide the result-oriented environment for new development frameworks [12]. These compensating adjustments might take time to have correcting effects on economy. Martin [12] provides insights on negative and positive hysteresis. While negative hysteresis occurs when an impact of the crisis lowers the long-term growth path of an economy, positive hysteresis occurs when the economy rebounds from the crisis affect and experiences higher levels of output/employment than in the pre-crisis time. See values of negative and positive hysteresis in Figure 1 and Figure 2.
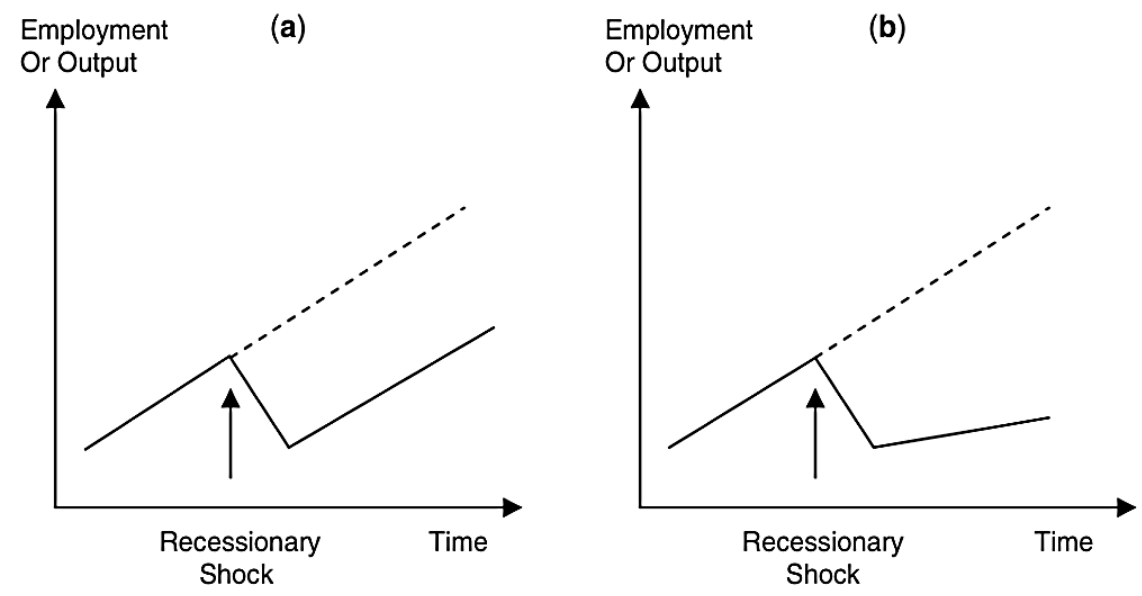

Fig. 1. Negative hysteretic impacts of the recessionary shock on a region's growth path: (a) permanent decline in level, resumption to pre-recession growth rate, (b) permanent decline in level and lower growth rate.

Source: [12]
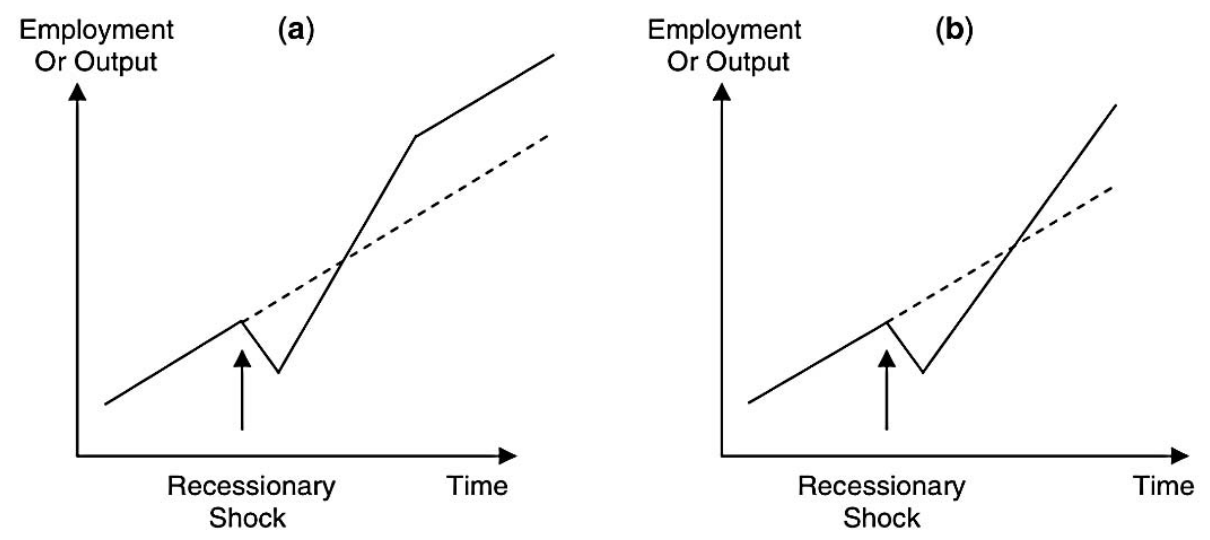

Fig. 2. Positive hysteretic impacts of the recessionary shock on a region's growth path: (a) recovery to higher level, resumption to pre-recession growth rate, (b) recovery to sustained higher growth rate.

Source: [12]

Researchers of economic hysteresis highlight the impact of recessionary shocks on national/regional labour markets [25, 14, 26, 27]. Hysteresis effects might lead to alteration of the 'normal' path of economic growth convergence which might have long-term effects 
on output and growth [28]. This eventually influences path dependency in economic growth [21].

However, the impact of the crisis on hysteresis convergence has not been studied yet in full. As it is known, the output changes after the crisis, hence convergence/divergence across countries might change after the crisis. The decade after the crisis helps to understand the long-term change in convergence in pre- and post-crisis times based on the change in output levels. Findings show a striking change in dynamics of convergence in time after the crisis of 2007 and prove the presence of hysteresis in the convergence process.

\section{Materials and Methods}

We will use values of GDP per capita across 110 countries in 1970-2016 [29]. As we have mentioned before, in the 1970-ies, it is possible that the oil crisis and collapse of Britton woods influenced convergence of countries with a common growth path (if the linear model is equally applicable to every country). That is why the analysed period starts in 1970. To show the change in convergence behaviours, we evaluated the recession impact on convergence prior to and after 2007.

We applied the methodology of Webber and White [10] to understand dynamics of convergence/divergence with/without switching based on concordance and discordance estimates.

According to [10], let us assume that the model looks like the following:

$$
\left(\frac{s_{i, t}}{s_{j, t}}\right)^{X}=\left(\frac{s_{i, t+T}}{s_{i, t+T}}\right),
$$

Assume that $\mathrm{s}_{\mathrm{i}}>\mathrm{s}_{\mathrm{j}}>0$.

By defining $\mathrm{X}_{\mathrm{ij}}$ as a solution for (6) and taking logarithms on both sides:

$$
X_{i, j}=\frac{\log \left(s_{i, t+T}\right)-\log \left(s_{j, t+T}\right)}{\log \left(s_{i, t}\right)-\log \left(s_{j, t}\right)} .
$$

In the research, we coded the solution as Type I, Type II, Type III, Type IV, and Type V showing types of behaviours of countries that demonstrates convergence/divergence with/without switching

If,

$\mathrm{X}_{\mathrm{i}, \mathrm{j}}>1$, then countries $i$ and $j$ show divergence in ratio without switching = Type $\mathrm{I}$;

$0<\mathrm{X}_{\mathrm{i}, \mathrm{j}}<1$, then countries $i$ and $j$ show convergence in ratio without switching = Type II;

$-1<\mathrm{X}_{\mathrm{i}, \mathrm{j}}<0$, then countries $i$ and $j$ show convergence in ratio with switching = Type III;

$-1>\mathrm{X}_{\mathrm{i}, \mathrm{j}}$, then countries $i$ and $j$ show divergence in ratio with switching $=$ Type IV;

$\mathrm{X}_{\mathrm{i}, \mathrm{j}}=0$, then countries have already merged and there cannot be any further convergence $=$ Type $\mathrm{V}$.

The study divides the period of 1970-2016 into two parts (1970-2006 and 2007-2016) to understand the effect of the global crisis of 2007 on dynamics of convergence/divergence. The study compares pre- and post-crisis dynamics to investigate the change in convergence/divergence with/without economy switching. Researchers calculate a percentage of each type of concordance/discordance in pre- and post-crisis periods to find out which type of behaviour dominates before and after the crisis. This will help to understand a change (if any) in behaviours of economies within the distribution. 


\section{Results}

To show some basic characteristics of GDP per capita, see Table 1 with descriptive statistics for four time periods.

Table 1. Descriptive statistics.

\begin{tabular}{|c|c|c|c|c|}
\hline Variable & Mean & Std. Dev & Min & Max \\
\hline gdp_1970 & 7236 & 9650 & 170 & 42138 \\
\hline gdp_2006 & 15513 & 21520 & 223 & 104943 \\
\hline gdp_2007 & 15966 & 22155 & 226 & 111968 \\
\hline gdp_2016 & 16009 & 21386 & 218 & 108601 \\
\hline
\end{tabular}

Standard deviation had been increasing until 2007 but declined to the values even lower than in 2006 or to the pre-crisis level. This shows that the data around the mean were less spread out in 2017 or converging to some extent. Similarly, in 2016, the minimum was 2 percent lower than prior to the crisis (in 2006) implying that poor countries became poorer after almost a decade of the crisis. Looking at the maximum value in 2016, we see slightly higher figures than in 2006, showing that rich countries were slightly better compared to their pre-crisis condition. Thus, the preliminary analysis shows that since the crisis, the poor ave been getting poorer and the rich have been getting richer (inequality between the rich and the poor has been increasing).

Table 2. Behaviours shown by countries, percentages.

\begin{tabular}{|c|c|c|c|c|}
\hline \multirow{2}{*}{\multicolumn{2}{|c|}{ Period }} & \multicolumn{3}{|c|}{ Percentages } \\
\hline & & $1970-2016$ & $1970-2006$ & $2007-2016$ \\
\hline Type 1 & Divergence without switching & $55 \%$ & $52 \%$ & $41 \%$ \\
\hline Type II & Convergence without switching & $32 \%$ & $30 \%$ & $56 \%$ \\
\hline Type III & Convergence with switching & $6 \%$ & $12 \%$ & $1 \%$ \\
\hline Type IV & Divergence with switching & $7 \%$ & $6 \%$ & $1 \%$ \\
\hline
\end{tabular}

Table 2 shows that in 1970-2016, Type I behaviour prevailed, i.e., 55 percent of countries diverged without switching. This means increased cross-national inequality because rich nations were getting richer and poor nations were getting poorer [8]. Looking at the breakout in the period before and after the crisis, we see strikingly different results. For instance, prior to the crisis, as expected, countries had been diverging and inequality had been increasing. However, after the crisis, the situation completely changed, and convergence took over. Countries converged without switching (56 percent), implying that rich and poor countries came together or promoted equal output levels after the crisis. Another important post-crisis implication is that countries did not lose their places/ranks as convergence and divergence with switching was one percent only. Thus, it seems that the world reached persistence. Intradistribution dynamics shows negligible mobility of countries. Thus, findings point out to post-crisis mobility stagnation.

The drastically changed convergence and divergence assume possible hysteretic outcomes of the crisis of 2007. The change in the convergence process might be a result of negative hysteresis in some countries and positive in others. The negative effect is when shocks or crises exert a downward shift in a country's growth path [12]. For instance, shocks might have a permanent impact on employment rates and lower rates by making employees redundant. Then it takes time for redundant employees to get into the system again. There might be many reasons for this delay, such as closure of particular sectors, thereby no demand for the skills that were in demand before. The demand for new skills creates a need for training and reskilling of redundant workers that might take time. In response to this situation, national output might decline for some time or contraction might be permanent. 
The positive hysteresis means that growth paths of countries experience an upward shift after the crisis. This might mean that post-crisis resurgence of the national output is higher than the pre-crisis level. This implies that in these countries, destructive effects of the recession were outweighed by result-oriented responses to the situation. Martin [12] presents some reasons behind the rebound of economic growth, such as optimistic business outlook and available spare capacity to increase output and employment rates, among others. Besides, positive hysteresis depends on how quickly economy adopts the change to recover.

Negative/positive hysteresis after the crisis is inevitable. The difference arises in adaptability of economies to changes. If an economy can outweigh negative effects of the crisis and get back to the pre-crisis level, the change becomes positive, and vice versa. Researchers make the stronger emphasis on the negative aspect of the crisis but in fact, the positive effect might overshadow the negative one and help economy to recover fast. Table 2 shows that after the crisis of 2007 some poor countries might have done far better compared to the pre-crisis level to come closer to richer nations. This might be because of two reasons: first, poor countries themselves tried to work hard and adapt to changes quickly. Second, investments from rich economies came to poor economies when investors realized higher potential of returns from poor economies.

The first was widely discussed by researchers and we call it resilience. The quicker economy rebounds and recovers from the crisis, the more resilient it becomes. Several studies create the framework to explain resilient characteristics of economies to prevent them from negative effects of future crises [30-31, 17,32]. The second did not gain a lot of attention of researchers, even though mobility of capital to poor economies in the light of realized higher returns is the basic finding within the neoclassical growth model. If mobility of capital/investment continues and factor price equalisation prevails, then poor and rich economies converge (see Table 2). Thus, after the crisis, some economies might have gained owing to their adaptability (resilience) whereas other economies - owing to foreign investments or multinational companies.

Multinational activities have recently proliferated, especially in developing nations. For instance, [33] reports that multinationals own or influence the supply chain accounting for $50+$ percent of the world trade and 40 percent of the stock market in Western countries. Multinationals are considered to raise employment rates and thereby increase citizens' earning capacities and economic performance in developing countries [34]. Although studies on multinational companies are in this respect limited, many researchers explored foreign direct investments' performance as a reaction to the crisis of 2007 [35-38]. Some of them [39] investigate mechanisms with which multinationals around the world responded to the crisis relative to local companies. Researchers found that multinationals located in the country where the crisis was severe in terms of a loss in demand and credit had done better than local companies. Besides, they underlined that multinational companies responded to adverse shocks by adjusting (inter)national production. Furthermore, Castro and Campos [40] show that the crisis forced Asian and Latin American countries to attract more foreign investments owing to specific policies on foreign capital and higher credibility by reviving growth (by 2011) compared to the developed nations.

Therefore, the reason for convergence of poor and rich countries might be growing foreign investments in developing nations. Foreign investments were weak immediately upon the crisis of 2007 and gained pace in around 3-4 years. Developing and resilient countries served as a credible source of investment after a lag of around three years upon the crisis, mostly owing to introduced policies to attract foreign investments and make the resultoriented environment to absorb their capability through improved infrastructure and human capital. These investments have the positive influence on economic performance in developing countries and cause higher employment rates. 


\section{Conclusion}

The research presents findings of evaluated hysteresis in convergence (appeared because of the global recession of 2007). The X-convergence technique is used to group convergence behaviours into four types based on cross-national differences in income per capita in the pairwise setting. Two dominating types of behaviours are Type I (divergence without switching) and Type II (convergence without switching). The research aims at the evaluation of convergence dynamics and the search for hysteresis in convergence and divergence after the crisis of 2007. Type I behaviour was the clearest before the crisis, i.e., poor and rich economies had diverged, and inequality had increased. However, after the crisis, Type II behaviour came to dominate in the process, implying convergence of per capita GDP rates across poor and rich economies. Therefore, findings suggest changed growth paths in many countries after the recession of 2007. The heterogeneous mix of countries (at different stages of development) in the sample might lead to overestimation/underestimation of an overall convergence/divergence percentage while using the X-convergence method. This might pose a limitation to this research. To address this issue, in future studies, researchers might use the method to group countries based on their similar growth trajectories which will help in the appropriate assessment of their convergence/divergence percentages.

\section{References}

1. N. Mankiw, D. Romer, D. Weil, The Quarterly Journal of Economics 107(2), 407437(1992)

2. R. Barro, X. Sala-i-Martin, Journal of Political Economy 100(2), 223-251 (1992)

3. R. Barro, The Economic Journal 125(585), 911-942 (2015)

4. D. Quah, The Scandinavian Journal of Economics 95(4), 427-443 (1993a)

5. D. Quah, European Economic Review 37(2/3), 426-434 (1993b)

6. D. Quah, The Economic Journal 106(437),1045-1055 (1996a)

7. D. Quah, European Economic Review 40(6), 1353-1375 (1996b)

8. D. Quah, Journal of Economic Growth 2(1), 27-59 (1997)

9. D. Webber, P. White, Regional Studies 37(8), 773-782 (2003)

10. D. Webber, P. White, Applied Economics Letters 16(18), 1805-1808 (2009)

11. R. Romer, Advanced macroeconomics (McGraw Hill, NewYork, 2001)

12. R. Martin, Journal of Economic Geography 12(1), 1-32 (2012)

13. A. Tubadji, P. Nijkamp, V. Angelis, Cambridge Journal of Regions, Economy and Society 9(1), 103-136 (2016)

14. B. Fingleton, H. Garretsen, R. Martin, Journal of Regional Science 52(1), 109-133 (2012)

15. D. Bailey, N. Berkeley, Regional Studies 48(11), 1797-1812 (2014)

16. J. Simmie, R. Martin, Cambridge Journal of Regions, Economy and Society 3(1), 2743 (2010)

17. R. Boschma, Regional Studies 49(5), 733-751 (2015)

18. N. Georgescu-Roegen, N. Roegen, Analytical economics: issues and problems (Harvard University Press, Cambridge, 1966)

19. R. Cross, Economics \& Philosophy 9(1), 53-74 (1993)

20. M. Göcke, Journal of Economic Surveys 16(2), 167-188 (2002) 
21. M. Setterfield, Hysteresis. Working Papers 1004 (Trinity College, Department of Economics, 2010)

22. R. Cross, A. Allan, On the history of hysteresis, in R. Cross (Ed.), Unemployment hysteresis and the natural rate hypothesis (Basil Black-well, New York, 1988)

23. K. Frenken, F. Van Oort, T. Verburg, Regional Studies 41(5), 685-697 (2007)

24. V. Cerra, U. Panizza, S. Saxena, Contemporary Economic Policy 31(2), 424-439 (2013)

25. E. Phelps, Inflation policy and unemployment theory - The cost-benefit approach to monetary planning (London, 1972)

26. J. Sachs, High unemployment in Europe: Diagnosis and policy implications. NBER Working Paper Series 1830 (Cambridge/MA, 1986)

27. A. Lindbeck, D. Snower, The American Economic Review 76(2), 235-239 (1986)

28. A. Dutt, J. Ros, Structural Change and Economic Dynamics 18(1), 75-99 (2007)

29. The World Bank Group. World Bank Open Data. Retrieved from https://data.worldbank.org

30. R. Martin, P. Sunley, Journal of Economic Geography 15(1), 1-42 (2015)

31. R. Francis, B. Bekera, Reliability Engineering \& System Safety 121, 90-103 (2014)

32. M. Welsh, The Geographical Journal 180(1), 15-26 (2014)

33. The Economists. The retreat of the global company. (2017). Retrieved from https://www.economist.com/news/briefing/21715653-biggest-business-idea-past-threedecades-deep-trouble-retreat-global

34. M. Herman, D. Chisholm, H. Leavell, Allied Academies International Conference, Academy for Studies in International Business 4(1), 5 (2004)

35. N. Bayraktar, Procedia Economics and Finance 5, 83-92 (2013)

36. A. Dornean, V. Işan, D. Oanea, Procedia Economics and Finance 3, 1012-1017 (2012)

37. V. Mariana, Annals of the University of Oradea, Economic Science Series 20(2), 41-45 (2011)

38. F. De Beule, D. Van Den Bulcke, The impact of the global economic crisis on foreign direct investment, in E. Florence, P. Defraigne (Eds.), Towards a New Development Paradigm in Twenty-first Century China: Economy, Society and Politics 49 (2012).

39. L. Alfaro, M. Chen, Surviving the global financial crisis: foreign direct investment and establishment performance. Harvard Business School Working Paper No. 10-110 (2010).

40. P. Castro, A. Campos, International Business Research 10(11), 206 (2017) 